\title{
Light spectrum preference of Nile Tilapia (Oreochromis niloticus) under different hunger levels
}

\author{
Guang Jin, Jian Zhao, Yadong Zhang, Gang Liu, Dezhao Liu, Songming Zhu, \\ Yufang Shao, Zhangying Ye* \\ (College of Biosystems Engineering and Food Science, Zhejiang University, Hangzhou 310058, China)
}

\begin{abstract}
In order to improve the light welfare of Nile tilapia in aquaculture, the influence of hunger level on light spectrum preference of Nile tilapia was explored in this study. The whole experiment was based on the emptying of the gastrointestinal contents, and carried out under the controlled laboratory conditions. The light spectrum preference was assessed by counting the head location of fish in each experimental tank, which containing seven compartments (i.e., red, blue, white, yellow, black, green and public area). $\quad \mathrm{t}$-Distributed Stochastic Neighbor Embedding (t-SNE) was adopted to visualize the hunger level-based dynamic preference on light spectrum in two-dimensional space. According to the clustering results, significant differences in light spectrum preferences of Nile tilapia, under the different hunger levels, were indicated. In addition, the average visit frequency in green compartment was significantly lower than that in other color compartments throughout the whole experiment, and the total visit frequency in red compartment was relatively higher during the whole experiment.
\end{abstract}

Keywords: light welfare, Nile tilapia, hunger level, light spectrum preference, t-Distributed Stochastic Neighbor Embedding DOI: $10.25165 / \mathrm{j}$.jjabe.20191205.4170

Citation: Jin G, Zhao J, Zhang Y D, Liu G, Liu D Z, Zhu S M, et al. Light spectrum preference of Nile Tilapia (Oreochromis niloticus) under different hunger levels. Int J Agric \& Biol Eng, 2019; 12(5): 51-57.

\section{Introduction}

Tilapia is an irreplaceable part in Chinese agricultural economy, making it the largest producer of tilapia worldwide ${ }^{[1]}$. With the increasing scarcity of water resource and the aggravation of the environmental pollution, industrial recirculating aquaculture systems (RAS) are becoming the trend in tilapia farming. As a consequence, controllable environmental parameters-based welfare farming of tilapia is feasible in RAS. Furthermore, the environmental parameters, a successful welfare farming requires, should can be regulated effectively to provide optimal conditions for the survival and growth of the cultured species ${ }^{[2]}$.

Light is one of the most important environmental factors in aquaculture, it has the non-negligible effects on ingestion, growth, development, and the survival of the aquatic organisms ${ }^{[3]}$. Many studies have been made to explore the lighting technique in tilapia farming. In earlier studies, photoperiod was the focus, such as the effects of photoperiod on growth patterns ${ }^{[4]}$ and seed reproduction $^{[5,6]}$. Then, with the popularization of the concept of

Received date: 2018-02-07 Accepted date: 2019-05-12

Biographies: Guang Jin, $\mathrm{PhD}$, research interests: fish welfare, Email: ronnie2005@126.com; Jian Zhao, PhD, research interests: aquacultural engineering and fish welfare, Email: jsjsjspzj@163.com; Yadong Zhang, Master candidate, research interest: aquacultural engineering, Email: 164516715@qq.com; Gang Liu, PhD candidate, research interest: aquacultural engineering, Email: 11513012@zju.edu.cn; Dezhao Liu, Researcher, research interest: agricultural engineering, Email: dezhaoliu@zju.edu.cn; Songming Zhu, Professor, research interests: agricultural engineering and aquacultural engineering, Email: zhusm@zju.edu.cn; Yushao Fang, Associate Professor, research interest: agricultural engineering, Email: shaoyf@zju.edu.cn. Guang Jin and Jian Zhao contribute equally to this article.

*Corresponding author: Zhangying Ye, Professor, research interest: agricultural engineering and aquacultural engineering. College of Biosystems Engineering and Food Science, Zhejiang University, Hangzhou 310058, China. Tel: +86-15168310563, Email: yzyzju@zju.edu.cn. welfare aquaculture, light spectrum and intensity were gradually paid attention to in tilapia culture. Light spectrum has been proven to be critical to the growth of Nile tilapia ${ }^{[7]}$. What's more, Volpato and Barreto ${ }^{[8]}$ found that blue light can prevent the stress of Nile tilapia compared to green and white lights, and this effect is not necessarily related to the light intensity. Furthermore, they also showed that red light can stimulate the feeding motivation of Nile tilapia, but would not improve growth ${ }^{[9]}$. As to light intensity, Carvalho et al. ${ }^{[10]}$ found that the aggressive behavior of Nile tilapia is affected by the light intensity. However, this effect would not change the dominance ranks of tilapia. In addition, similar to photoperiod, light intensity as well as the light spectrum is also closely related to the reproduction of Nile tilapia ${ }^{[5,11]}$. The above works are regarding the effect of the light on fish internal states, however, in terms of fish welfare, making clear whether the effective lights are what the fish prefer is the critical problem that needs to be solved first ${ }^{[12]}$. Although some researches have been done to explore the light preference of Nile tilapia ${ }^{[12,13]}$, the fish internal physiological changes were not considered. Thus, distangling whether the internal physiological status would affect the light preference of Nile tilapia is of great significance to fish welfare.

Hunger level is an important factor affecting the fish welfare in aquaculture ${ }^{[14,15]}$, many works have been done to protect the feeding welfare of fish in aquaculture, especially in $\operatorname{RAS}^{[16,17]}$. Nevertheless, in consideration of the feeding cost and feeding rhythm, generally, the cultured species were only fed at the predetermined times in aquaculture ${ }^{[18,19]}$. Sometimes, the cultured species even have to be fasted for a long time because of the sickness $^{[20]}$ or long-distance transport ${ }^{[21]}$. As a consequence, hunger stress is inevitable in real aquaculture, and the hunger level of fish varies with the emptying of the gastrointestinal contents ${ }^{[22]}$. Now, few works on the interaction between the lighting and the hunger level of fish (not only for tilapia) have been reported. 
Therefore, to better guarantee the light welfare of fish, the light spectrum preference of Nile tilapia under the different hunger levels will be explored in this research. It is hypothesized that the light spectrum preference of Nile tilapia would be dynamic with the change of the hunger level.

In this study, light-emitting diode (LED) was adopted as the light source because of its great prospect in the development of RAS ${ }^{[23]}$. In addition, in view of the fact that tilapia is territorial and aggressive ${ }^{[24]}$, thus, in order to avoid the disturbance caused by the interaction between individuals, only one fish was kept in each $\operatorname{tank}^{[25]}$.

\section{Materials and methods}

All experimental protocols in this study were approved by the Committee of the Care and Use of Animals of Zhejiang University. The methods in this study were carried out in strict accordance with the guidelines of the Association for the Study of Animal Behavior Use of Zhejiang University.

\subsection{Fish}

Nile tilapia $(33.67 \pm 2.49) \mathrm{g}$ used in this study were selected from the same tank, and having higher growth rates than the other individuals $(24.14 \pm 3.72) \mathrm{g}$. They were provided by Xiong Feng Fry Co. Ltd., Guangdong, China, and first held in RAS (light blue tanks, but, with the white lighting environment) for one and half months. Before the experiment, fish were kept in experimental tanks for $3 \mathrm{~d}$ (one fish per tank) to make them accustomed to the new environment. During the acclimation phase, fish were fed 3 times per day (at 09:55, 15:55, and 21:55, respectively). During each feeding, food was delivered to the fish manually. In addition, floating pellet (Tong Wei Co., Ltd., Hainan, China) was used during the whole experiment.

\subsection{Experimental setup}

Each experimental system (three sets in total) was made up of a tank, a lighting system and a monitoring system. For the former, each tank $(50 \mathrm{~cm}$ radius and $60 \mathrm{~cm}$ depth; Figure 1a) was divided into seven compartments, these compartments (signed as color compartments) have the same area except the middle one (signed as public compartment). The aerating apparatus was put in the middle of the public compartment. Each color compartment was connected to the public compartment through a $10 \mathrm{~cm} \times 10 \mathrm{~cm}$ passageway on the bottom. The size of the passageway between every two adjacent color compartments is $15 \mathrm{~cm} \times 10 \mathrm{~cm}$. The whole experiment was executed under the controllable laboratory conditions where the temperature and humidity were constant: dissolved oxygen (DO) at $(8.67 \pm 0.31) \mathrm{mg} / \mathrm{L}$, total ammonia nitrogen $(\mathrm{TAN})<0.25 \mathrm{mg} / \mathrm{L}$, chemical oxygen demand (COD) $<1.50 \mathrm{mg} / \mathrm{L}$, water temperature at $(27.41 \pm 0.22)^{\circ} \mathrm{C}$, pH at $7.82 \pm 0.35$ and water depth at $(11.57 \pm 0.33) \mathrm{cm}$.

To the lighting system (Figure 1b), five different LED lights (Model OG-SX-90-CL-CJ, Zhejiang, China), involving red, yellow, green, blue and white, were hung inside the tank and above the water surface. Besides the white light (peak wavelengths: $455 \mathrm{~nm}$ and $560 \mathrm{~nm}$ ), the peak wavelengths of the other four light sources are $620 \mathrm{~nm}, 595 \mathrm{~nm}, 520 \mathrm{~nm}$ and $450 \mathrm{~nm}$, respectively. There was no light in the black compartment. To ensure the better light environment, each compartment was covered with the corresponding reflective transfer film. Furthermore, to avoid the light interference from the adjacent tanks, the out wall of each tank was covered with the black wallpaper. During the whole experiment, the average light intensity $(1.91 \pm 0.38) \mu \mathrm{mol} / \mathrm{m}^{2}$ of each LED was maintained the same as much as possible by adjusting the distance between LED and the water surface.

As for the monitoring system, to guarantee the full view-angle coverage of the focal tank, each tank was equipped with two cameras (2CD1221-I3, Hikvision, Zhejiang, China) which were mounted above the tank.

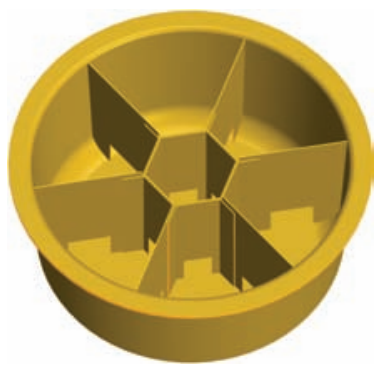

a. 3D structural map of the tank

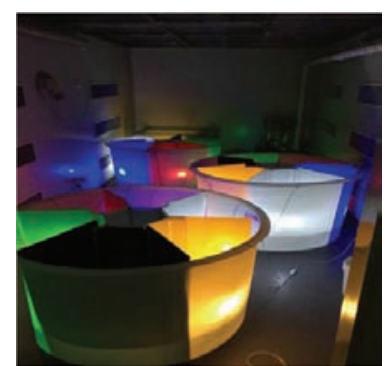

b. Experimental picture
Figure 1 Experimental setup: 3D structural map of the tank and experimental pictures (with no wallpaper covering the out wall of the tanks)

\subsection{Experimental design}

Experiment in this study was done in August, 2016. The whole experiment was based on the emptying of the gastrointestinal contents ${ }^{[22]}$. Generally speaking, the longer the emptying of the gastrointestinal contents, the higher the hunger level of the fish. Each fish was first put in the pubic compartment when it was transferred to the experimental tank. Before the experiment, fish in all tanks (from the same group) were restricted from feeding for $36 \mathrm{~h}$ to guarantee that minimal food remained in the stomach and intestine. At the beginning of the experiment, fish from the same group were fed to over-satiation simultaneously, and then fish were deprived of food for $36 \mathrm{~h}$ once again. To better visualize the hunger level-based dynamic preference on LED lights, three experimental groups (three repetitions each group) were carried out at 09:55, 15:55, and 21:55, respectively. The reason for starting the different groups at the different time is to avoid the interference from fish circadian rhythm as much as possible. And as shown in Figure $1 \mathrm{~b}$, to eliminate the influence of the magnetic-field perception-based location-choosing of the fish ${ }^{[26]}$ as much as possible, the same color compartments in three repetitions were put in different directions (at intervals of $60^{\circ}$ ). In addition, another three repetitions (with the same LED inside each tank, but the lights were off) were carried out at 09:55 as the control group.

In this experiment, cameras were triggered to record automatically after each over-satiation feeding (5 min delay). And it's worth noting that we set the public compartment of the tank as the delivering area of the pellet feed. The pellet feed would not transfer to the color compartments because of the fact that the water depth $(11.57 \pm 0.33) \mathrm{cm}$ was higher than the height of the passageway $(10 \mathrm{~cm})$. As a consequence, in terms of feeding, the disturbance from the color compartments would be avoided owing to the fact that fish would not feed in color compartments.

\subsection{Data analysis}

In this study, preference on light spectrum was assessed by counting the head location of the fish, and the location was recorded per second manually. The sampling was implemented at intervals of $2 \mathrm{~h}$, and each sampling lasted $2 \mathrm{~h}$. Data were represented as mean \pm standard error (SE). Hunger level-based selection differences on light spectrum were analyzed by t-Distributed Stochastic Neighbor Embedding (t-SNE) $)^{[27]}$ and one-way ANOVA, with $p<0.05$ indicating a significant difference. All statistical analysis was performed using Python 2.7 and Matlab R2013a. Charts were drawn using Matlab R2013a. 


\section{Results and discussion}

Figure 2 shows the description of the response time of Nile tilapia in different compartments (including the public compartment). Each data point was calculated as follows.

$$
\begin{aligned}
& P_{i}=\left(N_{i} / \operatorname{sum}(N)\right) \times 100 \%, \\
& i \in\{\text { red }, \text { blue, white, yellow, black, green, public }\}
\end{aligned}
$$

where, $N_{i}$ denotes the response time (in seconds) of the fish staying in compartment $i$, and $\operatorname{sum}(N)$ is a constant representing the total time of each sampling time, i.e., $7200 \mathrm{~s}$.

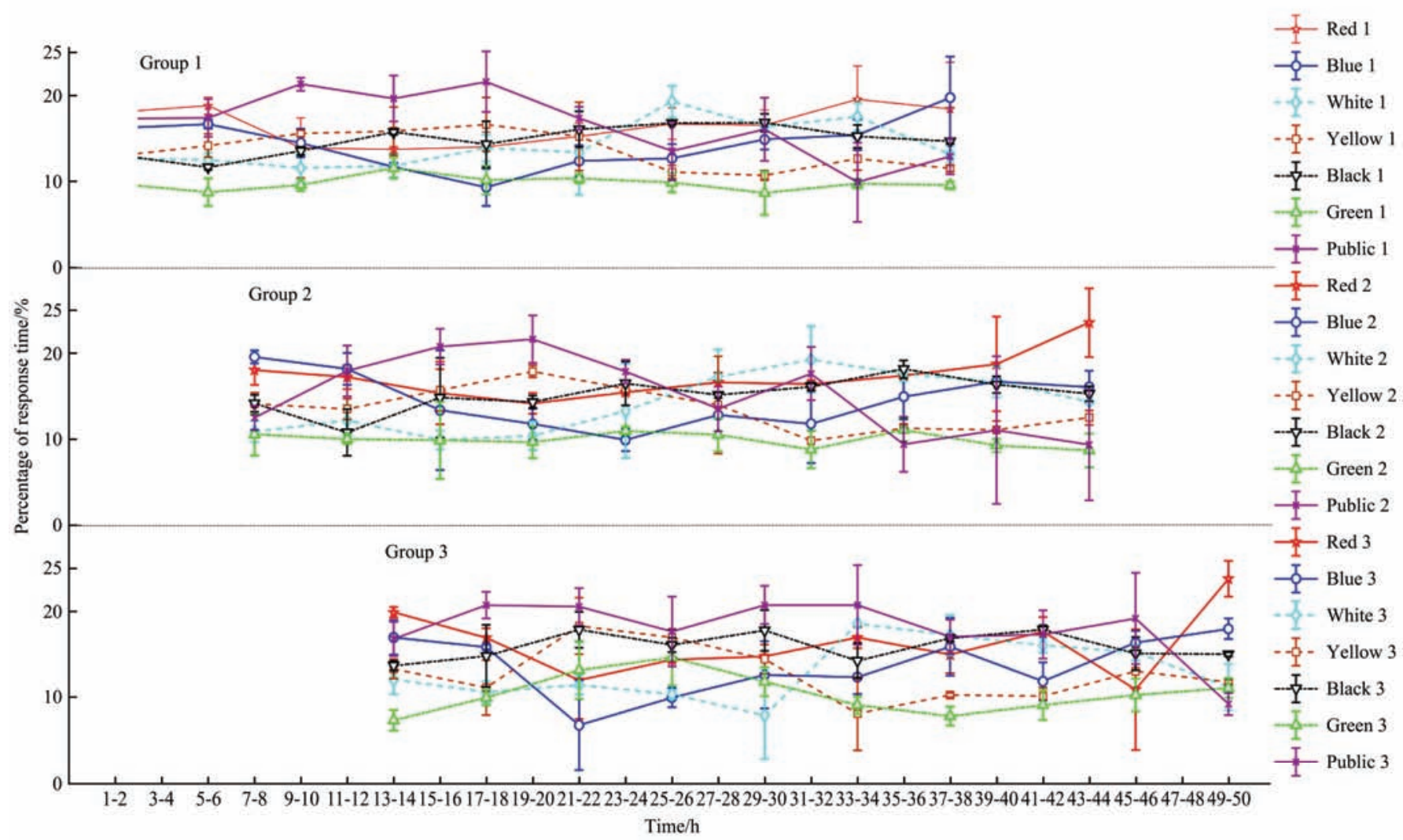

Figure 2 Description of the response time of Nile tilapia in different compartments (including the public compartment) at intervals of $2 \mathrm{~h}$

As illustrated in Figure 2, with the increase of the evacuation of the gastrointestinal contents of the fish, $P_{\text {public }}$ has a significant increase in the early stages of the whole experiment. This phenomenon conforms to the intensification of the hunger level of the fish ${ }^{[28]}$. Accordingly, the light spectrum preference of the focal fish also changes with the increase of the hunger level. Nevertheless, $P_{\text {public }}$ trends down over the last few stages of the experiment. This may be an energy-conserving mechanism to the fasted Nile tilapia ${ }^{[29]}$, namely, to save the energy, fish would prefer to stay in a fixed and comfortable place than swim around for food. Furthermore, although these three experimental groups were triggered at different times, taking the description in Figure 2 and the significance analysis in Table 1 (pre-processed by equation (2); $\mathrm{T} n$ represents the different sampling time after being fed to over-satiation, $1 \leq n \leq 10$ ) together, the changing trends of the light spectrum preference in three groups have certain similarities. To some extent, this can be explained that, in contrast to the circadian rhythm of Nile tilapia, the hunger level has a greater impact on the selection of the light spectrum.

$$
\begin{aligned}
& P_{1 i}=\left(N_{i} /\left(\operatorname{sum}(N)-N_{\text {public }}\right)\right) \times 100 \%, \\
& i \in\{\text { red }, \text { blue }, \text { white, yellow, black, green }\}
\end{aligned}
$$

As demonstrated in Figure 3, the preference difference on different compartments between three experimental groups (the average value of three groups) and the control group (no LED inside) is significant. It reinforces the fact that light spectrum has

\begin{tabular}{|c|c|c|c|c|c|c|c|}
\hline \multirow{2}{*}{ Time } & \multirow{2}{*}{ Experimental group } & \multicolumn{6}{|c|}{ Color compartment } \\
\hline & & Red & Blue & White & Yellow & Black & Green \\
\hline \multirow{2}{*}{$\mathrm{T} 1$} & Group1 & $21.80 \pm 3.02^{\mathrm{a}}$ & $19.60 \pm 1.44^{\mathrm{a}}$ & $15.29 \pm 1.82^{\mathrm{a}}$ & $15.67 \pm 0.85^{\mathrm{a}}$ & $15.87 \pm 1.15^{\mathrm{a}}$ & $11.78 \pm 4.41^{\mathrm{a}}$ \\
\hline & Group3 & $23.88 \pm 0.87^{\mathrm{a}}$ & $20.39 \pm 1.93^{\mathrm{a}}$ & $14.49 \pm 2.35^{\mathrm{a}}$ & $15.99 \pm 1.00^{\mathrm{a}}$ & $16.46 \pm 0.94^{\mathrm{a}}$ & $8.80 \pm 1.30^{\mathrm{a}}$ \\
\hline \multirow{3}{*}{$\mathrm{T} 2$} & Group1 & $22.77 \pm 0.57^{\mathrm{a}}$ & $20.20 \pm 0.16^{\mathrm{a}}$ & $15.15 \pm 0.58^{\mathrm{a}}$ & $17.16 \pm 1.29^{\mathrm{a}}$ & $14.13 \pm 0.27^{\mathrm{a}}$ & $10.59 \pm 2.17^{\mathrm{a}}$ \\
\hline & Group2 & $21.01 \pm 0.98^{\mathrm{a}}$ & $22.19 \pm 1.46^{\mathrm{a}}$ & $14.88 \pm 1.66^{\mathrm{a}}$ & $16.49 \pm 0.90^{\mathrm{a}}$ & $13.19 \pm 3.81^{\mathrm{a}}$ & $12.24 \pm 1.13^{\mathrm{a}}$ \\
\hline & Group3 & $21.34 \pm 0.99^{\mathrm{a}}$ & $19.99 \pm 0.09^{\mathrm{a}}$ & $13.39 \pm 1.31^{\mathrm{a}}$ & $14.05 \pm 3.80^{\mathrm{a}}$ & $18.68 \pm 4.93^{\mathrm{a}}$ & $12.56 \pm 1.34^{\mathrm{a}}$ \\
\hline \multirow{3}{*}{$\mathrm{T} 3$} & Group1 & $17.69 \pm 4.45^{\mathrm{a}}$ & $18.39 \pm 2.08^{\mathrm{a}}$ & $14.69 \pm 2.01^{\mathrm{a}}$ & $19.82 \pm 0.65^{\mathrm{a}}$ & $17.23 \pm 0.58^{\mathrm{a}}$ & $12.18 \pm 0.83^{\mathrm{a}}$ \\
\hline & Group2 & $19.45 \pm 5.12^{\mathrm{a}}$ & $16.90 \pm 9.26^{\mathrm{a}}$ & $12.57 \pm 1.07^{\mathrm{a}}$ & $19.85 \pm 2.50^{\mathrm{a}}$ & $18.75 \pm 5.44^{\mathrm{a}}$ & $12.49 \pm 5.36^{\mathrm{a}}$ \\
\hline & Group3 & $15.07 \pm 5.50^{\mathrm{a}}$ & $8.49 \pm 6.56^{\mathrm{a}}$ & $14.40 \pm 0.96^{\mathrm{a}}$ & $23.03 \pm 4.77^{\mathrm{a}}$ & $22.46 \pm 2.77^{\mathrm{a}}$ & $16.55 \pm 4.62^{\mathrm{a}}$ \\
\hline
\end{tabular}
an obvious impact on the selection of the compartments for Nile tilapia.

Table 1 Significance analysis of the response time in different color compartments between three experimental groups (\%) 


\begin{tabular}{|c|c|c|c|c|c|c|c|}
\hline \multirow{2}{*}{ Time } & \multirow{2}{*}{ Experimental group } & \multicolumn{6}{|c|}{ Color compartment } \\
\hline & & Red & Blue & White & Yellow & Black & Green \\
\hline \multirow{3}{*}{$\mathrm{T} 4$} & Group1 & $17.06 \pm 0.82^{\mathrm{a}}$ & $14.55 \pm 0.90^{\mathrm{a}}$ & $14.71 \pm 2.03^{\mathrm{a}}$ & $19.70 \pm 2.96^{\mathrm{b}}$ & $19.60 \pm 0.73^{\mathrm{a}}$ & $14.38 \pm 1.06^{\mathrm{a}}$ \\
\hline & Group2 & $18.10 \pm 2.08^{\mathrm{a}}$ & $15.05 \pm 2.03^{\mathrm{a}}$ & $13.32 \pm 1.69^{\mathrm{a}}$ & $22.86 \pm 0.81^{\mathrm{a}}$ & $18.30 \pm 0.44^{\mathrm{a}}$ & $12.38 \pm 2.44^{\mathrm{a}}$ \\
\hline & Group3 & $17.44 \pm 0.99^{\mathrm{a}}$ & $12.11 \pm 1.83^{\mathrm{a}}$ & $12.57 \pm 0.54^{\mathrm{a}}$ & $20.59 \pm 0.72^{\mathrm{b}}$ & $19.53 \pm 0.38^{\mathrm{a}}$ & $17.76 \pm 3.08^{\mathrm{a}}$ \\
\hline \multirow{2}{*}{$\mathrm{T} 5$} & Group1 & $17.88 \pm 1.46^{\mathrm{a}}$ & $11.91 \pm 2.27^{\mathrm{a}}$ & $17.74 \pm 2.82^{\mathrm{a}}$ & $21.23 \pm 5.09^{\mathrm{a}}$ & $18.29 \pm 2.69^{\mathrm{a}}$ & $12.97 \pm 1.60^{\mathrm{a}}$ \\
\hline & Group3 & $18.61 \pm 0.45^{\mathrm{a}}$ & $15.91 \pm 4.59^{\mathrm{a}}$ & $9.97 \pm 6.39^{\mathrm{a}}$ & $18.20 \pm 2.60^{\mathrm{a}}$ & $22.43 \pm 2.61^{\mathrm{a}}$ & $14.89 \pm 1.79^{\mathrm{a}}$ \\
\hline \multirow{3}{*}{ T6 } & Group1 & $18.45 \pm 2.00^{\mathrm{a}}$ & $14.98 \pm 1.99^{\mathrm{a}}$ & $16.17 \pm 6.04^{\mathrm{a}}$ & $18.45 \pm 4.67^{\mathrm{a}}$ & $19.43 \pm 2.31^{\mathrm{a}}$ & $12.52 \pm 0.84^{\mathrm{a}}$ \\
\hline & Group2 & $19.25 \pm 1.58^{\mathrm{a}}$ & $14.83 \pm 3.14^{\mathrm{a}}$ & $20.02 \pm 3.87^{\mathrm{a}}$ & $16.20 \pm 6.40^{\mathrm{a}}$ & $17.53 \pm 0.19^{\mathrm{a}}$ & $12.18 \pm 2.15^{\mathrm{a}}$ \\
\hline & Group3 & $21.38 \pm 2.83^{\mathrm{a}}$ & $15.58 \pm 1.99^{\mathrm{a}}$ & $23.39 \pm 4.27^{\mathrm{a}}$ & $10.22 \pm 4.78^{\mathrm{a}}$ & $17.98 \pm 1.81^{\mathrm{a}}$ & $11.46 \pm 0.84^{\mathrm{a}}$ \\
\hline \multirow[b]{2}{*}{$\mathrm{T} 7$} & Group1 & $19.34 \pm 1.42^{\mathrm{a}}$ & $14.67 \pm 1.35^{\mathrm{a}}$ & $22.31 \pm 2.90^{\mathrm{a}}$ & $12.85 \pm 0.41^{\mathrm{a}}$ & $19.42 \pm 0.74^{\mathrm{a}}$ & $11.41 \pm 0.84^{\mathrm{a}}$ \\
\hline & Group2 & $19.92 \pm 1.01^{\mathrm{a}}$ & $12.35 \pm 4.97^{\mathrm{a}}$ & $23.42 \pm 3.81^{\mathrm{a}}$ & $13.99 \pm 1.97^{\mathrm{a}}$ & $19.60 \pm 0.32^{\mathrm{a}}$ & $10.73 \pm 2.22^{\mathrm{a}}$ \\
\hline \multirow{3}{*}{$\mathrm{T} 8$} & Group1 & $19.67 \pm 1.34^{\mathrm{a}}$ & $17.72 \pm 2.15^{\mathrm{a}}$ & $19.49 \pm 1.05^{\mathrm{a}}$ & $12.76 \pm 1.22^{\mathrm{a}}$ & $20.05 \pm 0.46^{\mathrm{a}}$ & $10.31 \pm 2.65^{\mathrm{a}}$ \\
\hline & Group2 & $19.22 \pm 0.64^{\mathrm{a}}$ & $16.53 \pm 2.46^{\mathrm{a}}$ & $19.46 \pm 1.16^{\mathrm{a}}$ & $12.44 \pm 0.72^{\mathrm{a}}$ & $20.07 \pm 1.62^{\mathrm{a}}$ & $12.28 \pm 1.13^{\mathrm{a}}$ \\
\hline & Group3 & $21.36 \pm 2.08^{\mathrm{a}}$ & $14.34 \pm 2.40^{\mathrm{a}}$ & $19.42 \pm 1.07^{\mathrm{a}}$ & $12.28 \pm 1.18^{\mathrm{a}}$ & $21.60 \pm 0.98^{\mathrm{a}}$ & $11.00 \pm 1.92^{\mathrm{a}}$ \\
\hline \multirow{3}{*}{ T9 } & Group1 & $21.69 \pm 3.13^{\mathrm{a}}$ & $17.10 \pm 2.77^{\mathrm{a}}$ & $19.44 \pm 0.91^{\mathrm{a}}$ & $14.03 \pm 0.82^{\mathrm{a}}$ & $16.93 \pm 2.09^{\mathrm{a}}$ & $10.81 \pm 0.20^{\mathrm{a}}$ \\
\hline & Group2 & $21.10 \pm 4.31^{\mathrm{a}}$ & $18.79 \pm 1.49^{\mathrm{a}}$ & $18.76 \pm 0.34^{\mathrm{a}}$ & $12.48 \pm 0.72^{\mathrm{a}}$ & $18.40 \pm 2.60^{\mathrm{a}}$ & $10.47 \pm 0.28^{\mathrm{a}}$ \\
\hline & Group3 & $13.49 \pm 7.91^{\mathrm{a}}$ & $20.22 \pm 2.47^{\mathrm{a}}$ & $18.81 \pm 0.30^{\mathrm{a}}$ & $16.10 \pm 4.13^{\mathrm{a}}$ & $18.68 \pm 1.52^{\mathrm{a}}$ & $12.70 \pm 2.94^{\mathrm{a}}$ \\
\hline \multirow{3}{*}{$\mathrm{T} 10$} & Group1 & $21.16 \pm 6.23^{\mathrm{a}}$ & $22.68 \pm 5.40^{\mathrm{a}}$ & $15.12 \pm 0.99^{\mathrm{a}}$ & $13.22 \pm 0.32^{\mathrm{a}}$ & $16.84 \pm 0.21^{\mathrm{a}}$ & $10.99 \pm 0.30^{\mathrm{a}}$ \\
\hline & Group2 & $26.03 \pm 2.12^{\mathrm{a}}$ & $17.77 \pm 0.85^{\mathrm{a}}$ & $15.90 \pm 2.79^{\mathrm{a}}$ & $13.81 \pm 0.48^{\mathrm{a}}$ & $16.88 \pm 0.63^{\mathrm{a}}$ & $9.63 \pm 1.39^{\mathrm{a}}$ \\
\hline & Group3 & $26.21 \pm 2.64^{\mathrm{a}}$ & $19.78 \pm 0.80^{\mathrm{a}}$ & $12.33 \pm 2.87^{\mathrm{a}}$ & $12.96 \pm 0.32^{\mathrm{a}}$ & $16.52 \pm 0.22^{\mathrm{a}}$ & $12.21 \pm 1.17^{\mathrm{a}}$ \\
\hline
\end{tabular}

Note: Means with the different letters are significantly different at $p<0.05$ level.
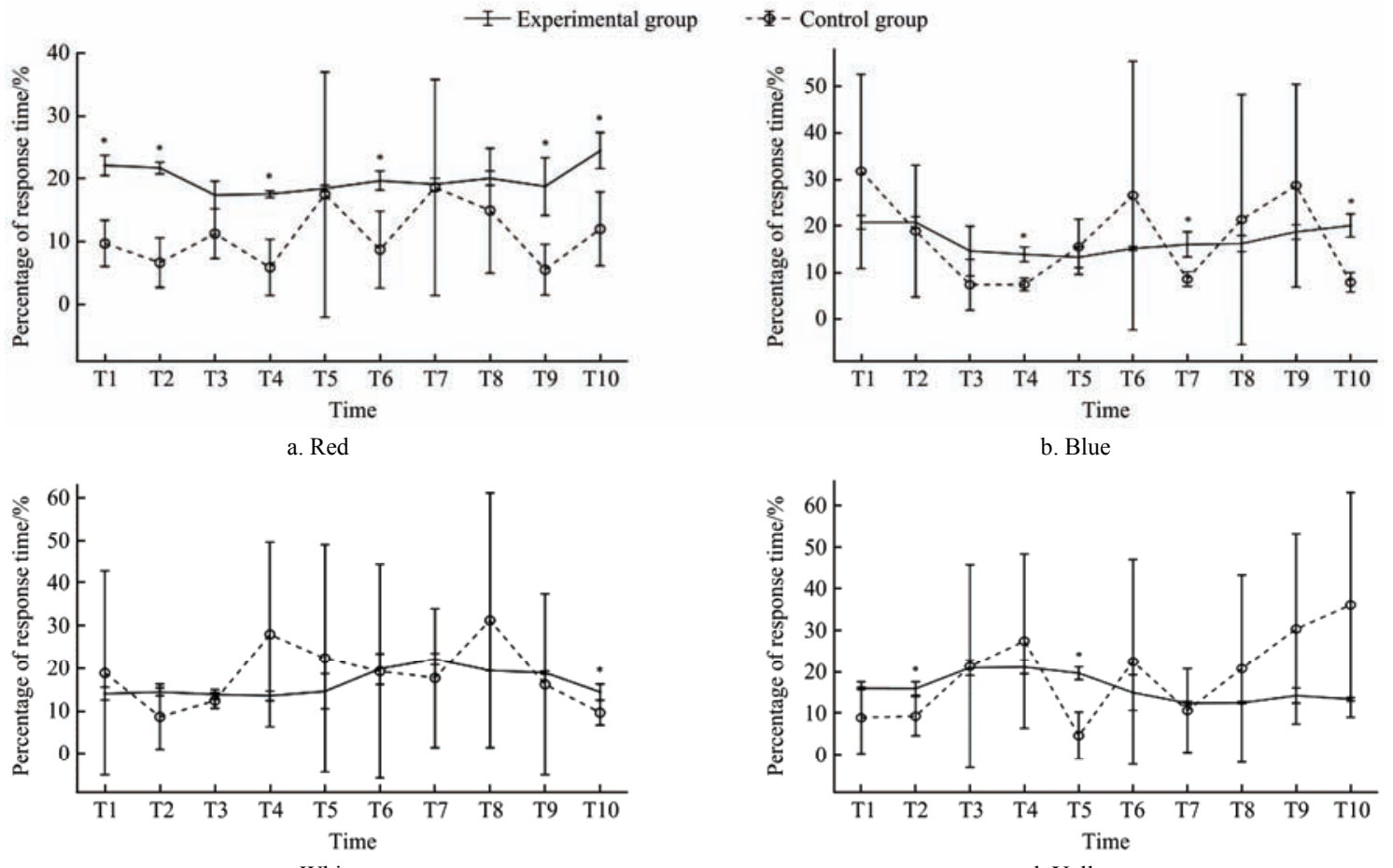

c. White

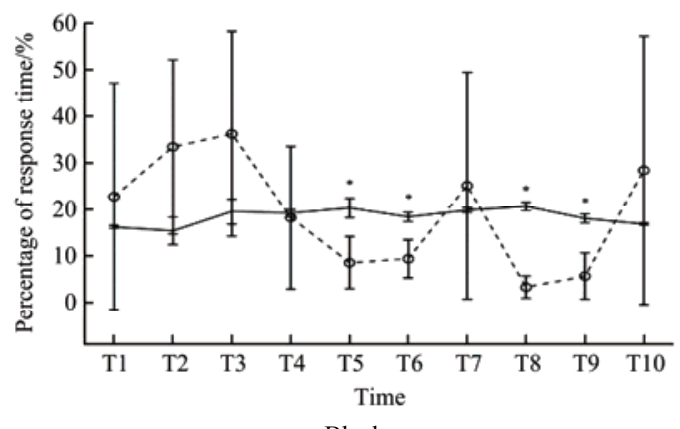

d. Yellow

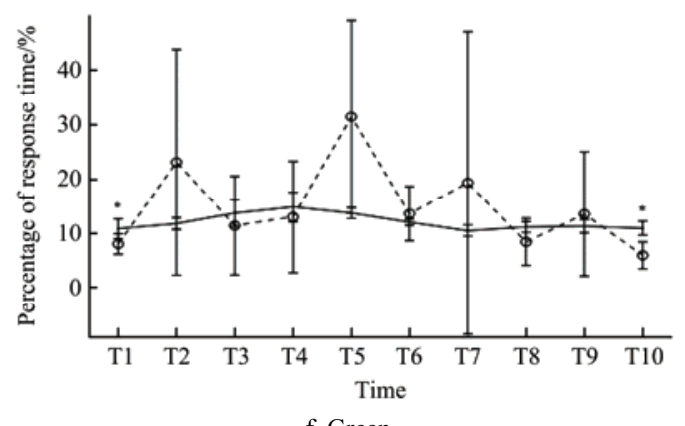

Figure 3 Description of the response time of Nile tilapia in red, blue, white, yellow, black and green color compartments. Means with * are significantly different at $p<0.05$ level between the experimental group and the control group during the same sampling time 
Analysis above is based on multidimensional data, it is hard to visualize the hunger level-based light spectrum preference of the fish. Thus, t-SNE based analysis was implemented in this section. $\mathrm{t}$-SNE, an effective nonlinear measure in visualizing the high dimensional data, is becoming more and more popular in data analysis $^{[30]}$. It has been proven that t-SNE has better performance than Principal Component Analysis (PCA) ${ }^{[31]}$ in visualization of the high dimensional data ${ }^{[32]}$. Nevertheless, in consideration of the characteristic of t-SNE (local structure-based analysis), to make the analysis more comprehensive, data in this study were initialized with PCA (global structure-based analysis) before being processed by t-SNE.

As shown in Figure 4, the hunger level-based light spectrum preference can be roughly divided into four clusters (marked in different colors): $\mathrm{T} 1$ and $\mathrm{T} 2$ (cluster 1), T3, T4 and T5 (cluster 2), T6, T7, T8 and T9 (cluster 3), T10 (cluster 4). Then, according to

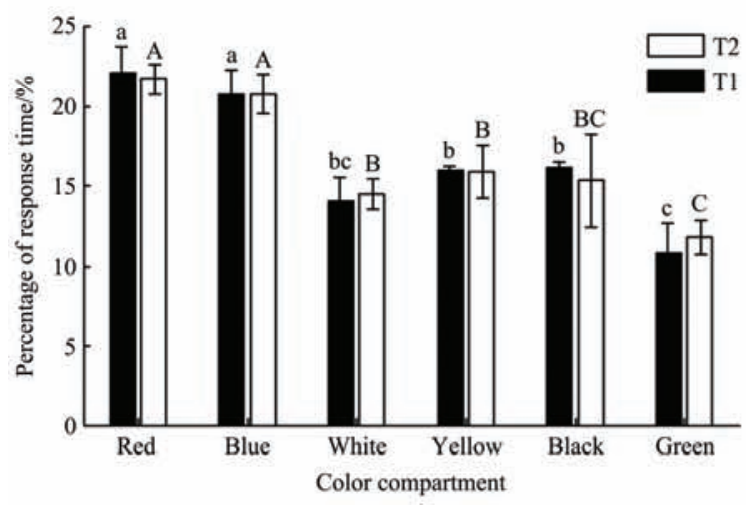

a. T1 and T2

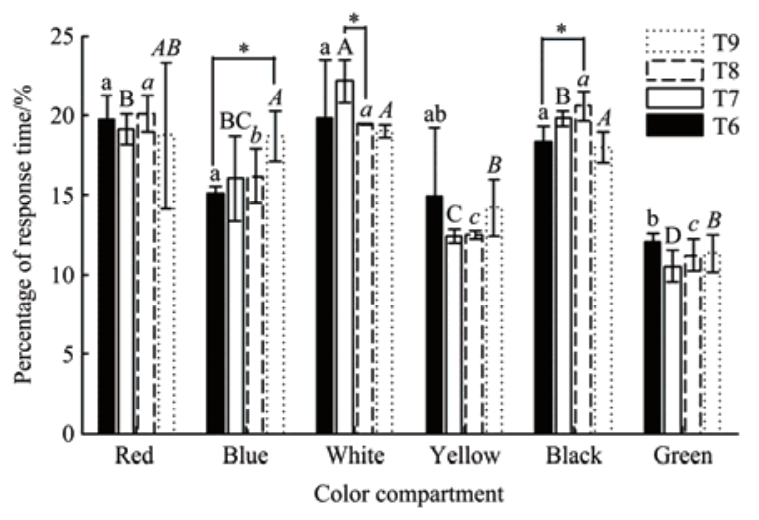

c. T6, T7, T8 and T9 the clustering result, the analysis of the hunger level-based light spectrum preference was detailed below.

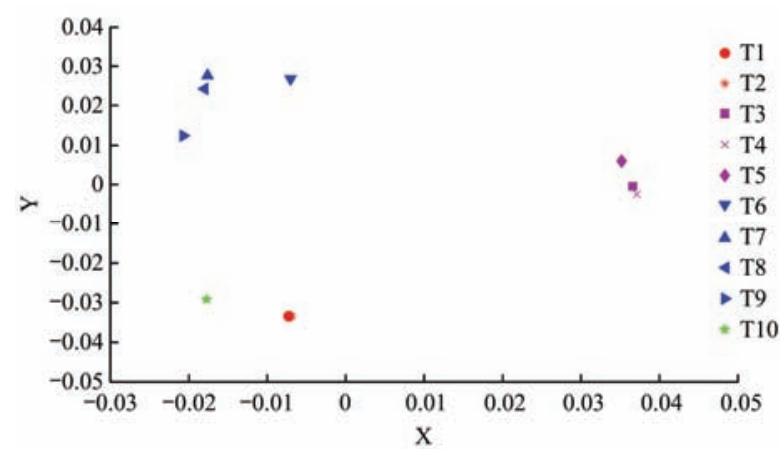

Figure 4 t-SNE based two-dimensional clustering analysis of the hunger level-based light spectrum preference (learning rate and iterations were set to 3 and 1000 , respectively)

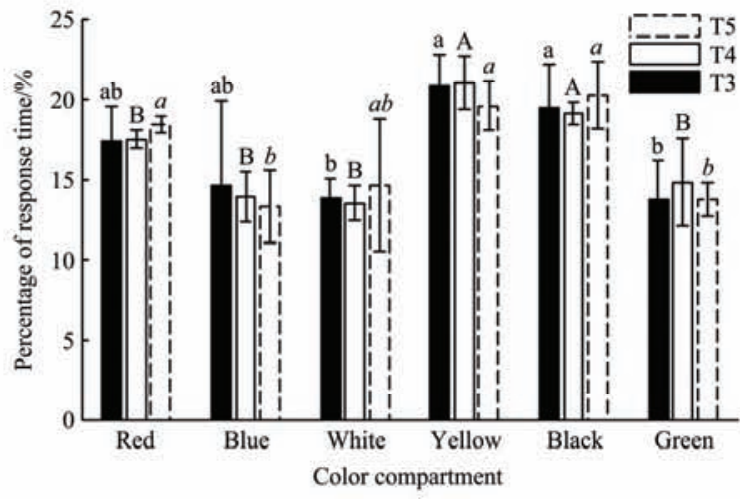

b. T3, T4 and T5

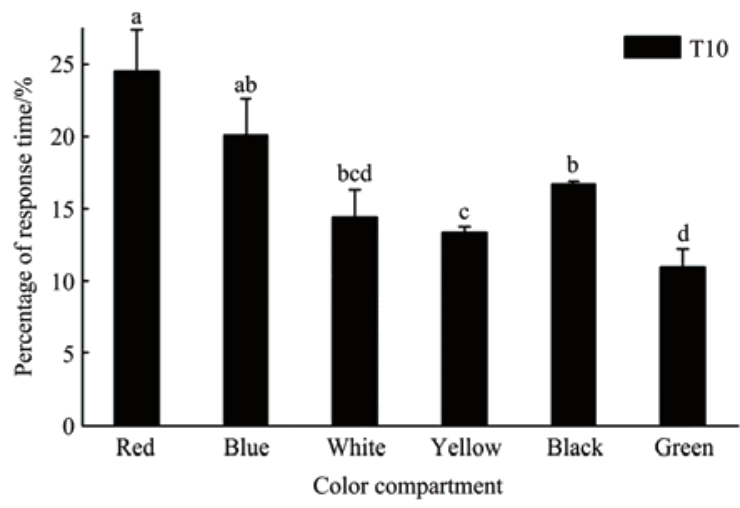

d. T10

Note: Different letters mean significantly different at $p<0.05$ level between the different light spectrums during the same sampling time. * means significantly different at $p<0.05$ level between the different sampling times for the same light spectrum.

Figure 5 Light spectrum preference analysis under different hunger levels (i.e., different sampling times)

During T1 and T2, the average visit frequencies in red and blue compartments are significantly higher than that in other color compartments (Figure 5a). However, for T3, T4 and T5, fish prefer to stay in yellow and black compartments (Figure 5b). As to T6, T7, T8 and T9, the average visit frequencies in white and black (except the black compartment in T7) are significantly higher than that in other color compartments (Figure 5c). In the last sampling time $\mathrm{T} 10$, only the average visit frequency in red compartment is significantly higher (Figure $5 \mathrm{~d}$ ).

Note that, the total visit frequency in red compartment is relatively higher during the whole experiment. The positive effect of the red light spectrum, acting on the feeding motivation of Nile tilapia, may be the reason ${ }^{[9]}$. Actually, the social hierarchy of the fish used in this study may also contribute to this phenomenon.
As stated in Materials and Methods, fish used in this experiment were chosen from the same batch, and having higher growth rates than other individuals. As a consequence, the experimental tilapia may have the higher hierarchy in fish school ${ }^{[33]}$. As found in Luchiari and Freire $^{[7]}$, red light spectrum could promote Nile tilapia to have higher heterogeneity in growth. In other words, red light spectrum may be more suitable for the growth of Nile tilapia with higher hierarchy than the ones with lower hierarchy. However, in general, red light spectrum was not recommended in aquaculture (not only for tilapia, but for many other species) due to the lower feed conversion rate and average growth of fish ${ }^{[9,25]}$.

In addition, short wavelengths, such as blue and green, have been reported to have the ability to promote the growth of the most studied species ${ }^{[3]}$. However, in this study, the average visit 
frequency in green compartment is significantly lower than that in other color compartments throughout the whole experiment. Increase of the cortisol under green light may be one of the main reasons for this phenomenon ${ }^{[34]}$. And this conjecture is also supported by Volpato et al. ${ }^{[9]}$ to some extent: the growth rate as well as the feed consumption efficiency of Nile tilapia was relatively lower under the green light.

In this study, the synergistic effect between the preferences of light intensity and spectrum under different hunger levels was not studied, it is a limitation to this experiment. In fact, the three-dimensional position of the fish can be a good indicator for fish preference on light intensity (deeper the fish, less the preference for light intensity). Whereas, this operation was hard to apply to our experiment due to the limits of our experimental setup.

As to the applicability of this study in aquaculture, though Nile tilapia shows an obvious dynamic preference on light spectrum under different hunger levels, challenges still exist in practical use. First, there are many other factors affecting fish preference on light spectrum in aquaculture, such as tank color $^{[35,36]}$, water temperature ${ }^{[37]}$, aquaculture density ${ }^{[35,38]}$, substrate $^{[39]}$ and so on. As a consequence, comprehensive consideration of the environment parameters should be done when the hunger level-based light spectrum preference of the cultured species is applied to real aquaculture. In the second place, for Nile tipalia, whether the preferred light spectrums (in conditions of different hunger levels) are good for fish growth hasn't been verified, as such, validation based on the long-term aquaculture should be done before applying the results obtained in this study to the actual production.

\section{Conclusions}

In order to improve the light welfare of Nile tilapia in aquaculture, the light spectrum preference of Nile tilapia, in conditions of the different hunger levels, was studied in this paper. By means of the emptying of the gastrointestinal contents-based experiment, the conspicuous dynamic preference of Nile tilapia for light spectrum was revealed with the help of t-SNE and PCA. In addition to this, Nile tilapia shows the significantly lower average visit frequency in green compartment than that in other color compartments throughout the whole experiment, and the total visit frequency of Nile tilapia in red compartment is relatively higher during the whole experiment. In this study, although lacking the validation of the long-term aquaculture, results obtained here provide a theoretical reference for the light welfare of the cultured species in aquaculture, especially for the hunger level-based light welfare.

\section{Acknowledgements}

This research was supported by the National Key R\&D Program of China (Grant No. 2017YFB0404000), the Key R\&D Program of Ningxia Hui Autonomous Region (Grant No. 2018BBF02009) and Open Fund of Yunnan Province Key Laboratory of Food Processing and Safety Control (Grant No. K16-507106-007). Any opinions, findings, and conclusions expressed in this publication are those of the authors and do not necessarily reflect the views of Zhejiang University.

\section{[References]}

[1] FAO. FishStatJ: A tool for fishery statistics analysis, version 1.0.1.
United Nations FAO, Rome, 2018.

[2] Gao X L, Zhang M, Tian H Q, Zheng J M, Li X, Song C B, et al. Effect of LED light quality on respiratory metabolism and activities of related enzymes of Haliotis discus hannai. Aquaculture, 2016; 452: 52-61.

[3] Villamizar N, Blanco-Vives B, Blanco-Vives H, Davie A, Carboni S, Sánchez-Vázquez F J. Effects of light during early larval development of some aquacultured teleosts: A review. Aquaculture, 2011; 315: 86-94.

[4] Tanaka K, Mugiya Y, Yamada J. Effect of Photoperiod and Feeding on Daily Growth Patterns in Otoliths of Juvenile Tilapia Nilotica. Fish B-NOAA, 1981; 79(3): 459-466.

[5] Ridha M T, Cruz E M. Effect of light intensity and photoperiod on Nile tilapia Oreochromis niloticus L. seed production. Aquac. Res, 2000; 31: 609-617.

[6] Ridha M T, Cruz E M, Al-Ameeri A A, Al-Ahmed A A. Effects of controlling temperature and light duration on seed production in tilapia, Oreochromis spilurus (Gunther). Aquac. Res, 1998; 29: 403-410.

[7] Luchiari A C, Freire F A M. Effects of environmental colour on growth of Nile tilapia, Oreochromis niloticus (Linnaeus, 1758), maintained individually or in groups. J. Appl. Ichthyol, 2009; 25(2): 162-167.

[8] Volpato G L, Barreto R E. Environmental blue light prevents stress in the fish Nile tilapia. Braz. J. Med. Biol. Res, 2001; 34: 1041-1045.

[9] Volpato G L, Bovi T S, de Freitas R H A, da Sliva D F, Delicio H C, Giaquinto P C, et al. Red Light Stimulates Feeding Motivation in Fish but Does Not Improve Growth. PLoS ONE, 2013; 8(3): e59134.

[10] Carvalho T B, Mendonca F Z, Costa-Ferrelra R S, Goncalves-de-Freltas E. The effect of increased light intensity on the aggressive behavior of the Nile tilapia, Oreochromis niloticus (Teleostei: Cichlidae). Zooglgia, 2013; 30(2): 125-129.

[11] Volpato G L, Duarte C R A, Luchiari A C. Environmental color affects Nile tilapia reproduction. Braz. J. Med. Biol. Res, 2004; 37: 479-483.

[12] Maia C M, Volpato G L. A history-based method to estimate animal preference. Sci. Rep., 2016; 6(1): 28328-28335.

[13] Maia C M, Ferguson B, Volpato G L, Braithwaite V A. Physical and psychological motivation tests of individual preferences in rainbow trout. J. Zool., 2017; 302(2): 108-118.

[14] Kiessling A, Vis H, van de Flik G, Mackenzie S. Welfare of farmed fish in present and future production systems. Fish Physiol. Biochem, 2012; 38: $1-3$.

[15] Chang C M, Fang W, Jao R C, Shyu C Z, Liao I C. Development of an intelligent feeding controller for indoor intensive culturing of eel. Aquacult. Eng, 2005; 32(2): 343-353.

[16] Ye Z Y, Zhao J, Zhu S M, Li J P, Han Z Y, Lu H D. Behavioral Characteristics and Statistics-Based Imaging Techniques in the Assessment and Optimization of Tilapia Feeding in a Recirculating Aquaculture System. Trans. ASABE, 2016; 52: 345-355.

[17] Liu Z, Li X, Fan L, Lu H, Liu L, Liu Y. Measuring feeding activity of fish in RAS using computer vision. Aquacult Eng, 2014; 60: 20-27.

[18] López-Olmeda J F, Noble C, Sánchez-Vázquez F J. Does feeding time affect fish welfare? Fish Physiol. Biochem, 2012; 38: 143-152.

[19] NRC. Nutrient requirements of fish and shrimp. Washington: National Academies Press, 2011.

[20] Gatlin III D M. Nutrition and fish health. Fish nutrition. London: Academic Press, 2002; pp.671-702.

[21] Berka R. The transport of live fish: a review (No. 48). United Nations FAO, Rome, 1986.

[22] Amundsen P K., Klemetsen A. Diet, gastric evacuation rates, and food consumption in a stunted population of arctic char, Salvelinus alpinus L., in Takvatn, northern Norway. J. Fish Biol, 1988; 33: 697-709.

[23] Song C B, Qiu D G, Wang J L, Yu K S, Liu Y. The application analysis of LED light source in recirculating aquaculture industry. China Illum. Eng. J, 2013; 16 (24): 127-132.

[24] Gonçalves-de-Freitas E, Teresa F B, Gomes F S, Giaquinto P C. Effect of water renewal on dominance hierarchy of juvenile Nile tilapia. Appl. Anim. Behav. Sci, 2008; 112(1): 187-195.

[25] Luchiari A C, Pirhonen J. Effects of ambient colour on colour preference and growth of juvenile rainbow trout Oncorhynchus mykiss (Walbaum). J. Fish Biol, 2008; 72(6): 1504-1514.

[26] Lohmann K J. Q\&A: Animal behaviour: Magnetic-field perception. Nature, 2010; 464(7292): 1140-1142.

[27] Maaten L V D, Hinton G. Visualizing data using t-SNE. J. Mach. Learn Res, 2008; 9(11): 2579-2605.

[28] AlZubi H S, Al-Nuaimy W, Buckley J, Young I. An Intelligent 
Behavior-Based Fish Feeding System. In: 13th International Muti-Conference on Systems, Singals \& Devices, 2016, Mar. 21-24, Leipzig, pp. 21-29.

[29] Sogard S M, Olla B L. Food deprivation affects vertical distribution and activity of a marine fish in a thermal gradient: potential energy-conserving mechanisms. Mar. Ecol-Prog. Ser, 1996; 133: 43-55.

[30] Berman G J, Choi D M, Bialek W, Shaevitz J W. Mapping the stereotyped behaviour of freely moving fruit flies. J. R. Soc. Interface, 2014; 99(11): 20140672.

[31] Smith L I. A tutorial on principal components analysis. Cornell University, USA, 2002; 51(52): 65.

[32] Bushati N, Smith J, Briscoe J, Watkins C. An intuitive graphical visualization technique for the interrogation of transcriptome data. Nucleic Acids Res, 2011; 39(17): 7380-7389.

[33] Villavicencio-Pulido J G, Nila-Luévano C, Guerrero-Cabrera L, García-Lozano H. A theoretical model with time-delay, competition and transitions among cohorts to study tilapia populations. Aquaculture, 2016; 463: 152-158.

[34] Barcellos L J G, Ritter F, Kreutz L C, Silva L B D, Cericato L, Quevedo R M. The color of illumination affects the stress response of jundiá
(Rhamdia quelen, Quoy \& Gaimard, Heptapteridae). Cienc. Rural, 2006; 36(4): 1249-1252.

[35] Karakatsouli N, Kassianos N, Papoutsoglou S E. Effects of rearing density and tank colour on juvenile sharpsnout seabream (Diplodus puntazzo) growth performance. Aquacult Int, 2015; 23(4): 943-953.

[36] Ullmann J F, Gallagher T, Hart N S, Barnes A C, Smullen R P, Collin S P, et al. Tank color increases growth, and alters color preference and spectral sensitivity, in barramundi (Lates calcarifer). Aquaculture, 2011; 322: 235-240.

[37] Lohne P, Imsland A K, Larsen S, Foss A, Pittman K. Interactive effect of photoperiod and temperature on the growth rates, muscle growth and feed intake in juvenile Atlantic halibut. Aquac. Res, 2012; 43(2): 187-197.

[38] Karakatsouli N, Papoutsoglou E S, Sotiropoulos N, Mourtikas D, Stigen-Martinsen T, Papoutsoglou S E. Effects of light spectrum, rearing density and light intensity on growth performance of scaled and mirror common carp Cyprinus carpio reared under recirculating system conditions. Aquacult. Eng, 2010; 42(3): 121-127.

[39] Reig L, Duarte S, Valero J, Oca J. Preference of cultured sole (Solea senegalensis) for different substrates differing in material, texture and colour. Aquacult. Eng, 2010; 42(2): 82-89. 